\title{
The deformability of the stress-strained concrete strips between the cracks during the short-term dynamic loading
}

\author{
Zaur Galyautdinov ${ }^{1, *}$, Oleg Kumpyak ${ }^{1}$, and Daud Galyautdinov ${ }^{1}$ \\ ${ }^{1}$ Tomsk State University of Architecture and Building, 634003 Tomsk, Russia
}

\begin{abstract}
Annotation. The formation of non-intersecting cracks in stress-strained ferroconcrete elements leads to separation of concrete strips between the cracks. The results of the experimental research indicate a significant decrease of the durability and deformability of the stress-strained concrete strips between cracks both under static and short-term dynamic loading. At the same time physico-mechanical properties depend on the straining deformations and rebars' inclination angle towards the cracks. The existing theoretical and experimental results evaluate only the durability of the concrete strips between the cracks. The current paper presents the results of experimental and theoretical studies on the dynamic deformability of the stress-strained discs between the cracks. The statistic analysis of the experimental data is done; on the basis of the analysis we suggest the dependencies, characterizing the deformability of the concrete strips during the short-term dynamic load depending on the level of the straining deformations and rebars' inclination angle towards the cracks.
\end{abstract}

\section{Introduction}

Single dynamic loadings on buildings and constructions make special demands of ensuring durability of separate constructions and the building as a whole [1 -3$]$. The trustworthiness of the construction deflected mode evaluation is determined, in the first place, by the concrete deformation model [4-6]. Modern models allow considering the main peculiarities of the dynamic deformation of concrete, reinforcement and ferroconcrete at all the stages of the construction work [7-13]. At the same time there is a range of issues, requiring an additional study, especially under high-speed loading conditions.

In flat-strained ferroconcrete constructions cracks appear in the areas of the main tensile stresses and, in general case, may be skew-oriented towards the bars of the mesh reinforcement. After appearing of a crack, the concrete cannot take tensile loads in the direction perpendicular to the crack direction; that is why all the tensile loads along this direction are transferred through the reinforcement. The loads in the orthogonal direction are taken by the concrete strips between the cracks.

The researches of the durability of concrete strips between cracks are presented in the works of our country and foreign scientists $[14,15,16,17]$. According to the results of the

*The corresponding author: gazr@yandex.ru 
experimental researches, we considered the influence of the samples' deformation level in the direction perpendicular to the crack and the inclination angle of the rebars towards the cracks. The scientists proposed the formulae for durability of the concrete strips between cracks under static $[16,17]$ and short-term dynamic loads $[18,19,20]$. At the same time, the issues of the deformability of the concrete strips between cracks under intense dynamic loads have not been scrutinized yet by now.

\section{The experimental research}

The current research presents the results of the experimental-theoretical analysis of the deformability of the stress-strained concrete strips between cracks under short-term dynamic load. We studied both the influence of the sample's deformation level and the inclination angle of the rebars towards the cracks' direction. The experimental researches were carried out on the ferroconcrete discs with fixed cracks (Ffig. 1).

a)

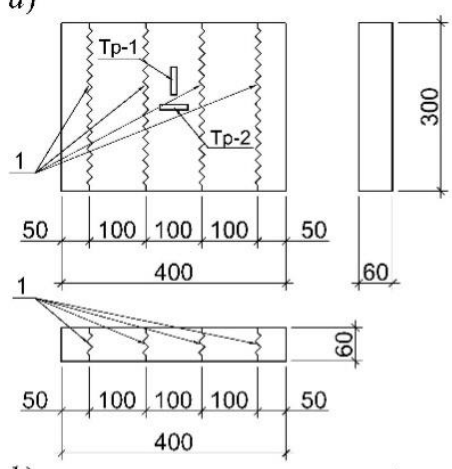

b)

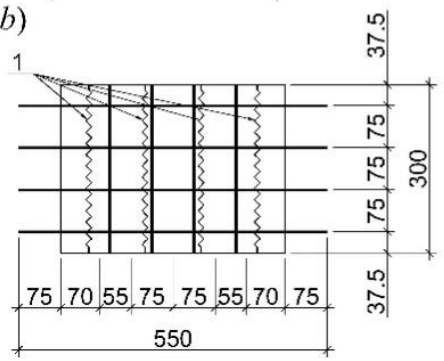

c)
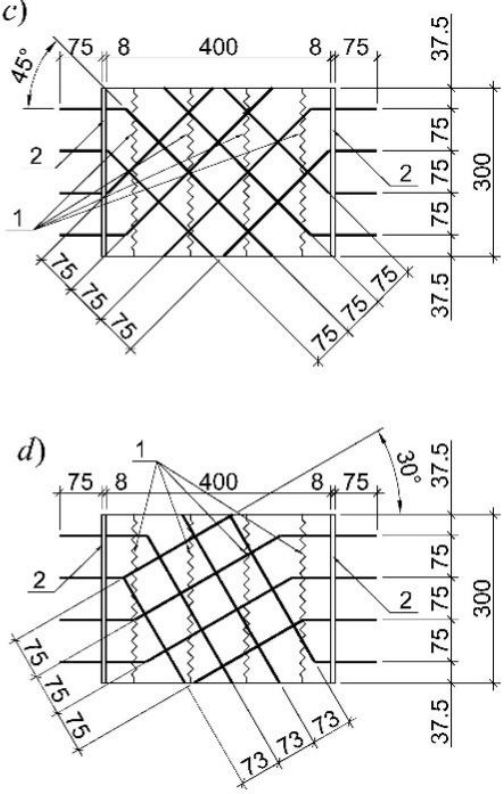

Fig. 1. The general view of the samples and the strain resistors placing on the concrete $(a)$ and the scheme of samples' reinforcement at different rebars' inclination angles towards the cracks $(b, c, d): 1$ - cracks; 2 - metal plates.

The general amount of the tested samples is 72, including: 23 samples at $\alpha=90^{\circ} ; 28-$ at $\alpha=45^{\circ}$ and $21-$ at $\alpha=30^{\circ}$. During concrete casting celluloid inserts were placed in the samples; then during the testing the cracks, dividing concrete blocks, appeared along the inserts. The rebars were placed at an angle towards the crack. The rebars' inclination angle towards the crack $\alpha$ was taken as equal to $90^{\circ}, 45^{\circ}$ and $30^{\circ}$. In the samples with $\alpha=30^{\circ}$ and $\alpha=45^{\circ}$ metal plates were placed on the outer edges (position 2, fig. 1); the plates prevented the mutual shift of the rebars. The main dimensions and schemes of samples' reinforcement are presented in Fig. 1. All the tested samples were produced from the heavy concrete of class B15. The mesh reinforcements were made from the reinforcement of class A400 with a diameter $8 \mathrm{~mm}$. 
During the tests the load was applied to the sample in two mutually orthogonal directions. The sample was strained along one direction, and was compressed along the other one (Fig. 2). The tensile stresses were fully transmitted through the reinforcement. The compressive stresses were transmitted to the concrete blocks between the cracks (Fig. 2). The tests were carried out at two stages; first, the strain was created up to the necessary level, and then the compression - till the destruction. During the strain there appeared the cracks, dividing the sample into concrete blocks, connected with each other by the reinforcement.

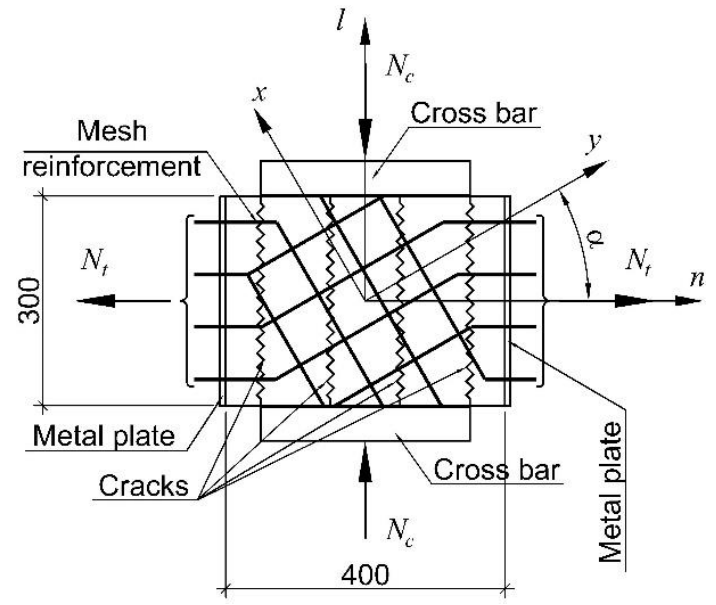

Fig. 2. The general view of the samples and the strain resistors placing on the concrete $(a)$ and the schemes of samples' reinforcement at different rebars' inclination angles towards the cracks $(b, c, d)$ : 1 - cracks; 2 - metal plates.

The tensile load on the sample was created by the hydraulic jack. The dynamic compression stresses were created due to the energy of the falling weight. The height of the weight falling and its size was chosen providing the total exhaustion of concrete strips bearing capacity between cracks at single load action.

Figure 3 presents the data on the deformability of concrete strips between cracks at different levels of samples tension $\varepsilon_{l}$, for the accepted rebars' inclination angles. According to the research results, it is obvious that the deformability of concrete strips between cracks decreases with the growth of the deformation level perpendicular to the crack $\varepsilon_{l}$ for all the values of the rebars' inclination angle towards the crack $\alpha$. Along with this, in contrast to the concrete strips' durability between cracks [17, 18, 19, 20], the influence of the angle $\alpha$ on their deformability is of a less degree, the level of ultimate strains $\varepsilon_{R p}$ lowering at different angles $\alpha$ is practically identical. The most intensive lowering of the concrete strips' deformability is observed in the interval $\varepsilon_{l}=100 \cdot 10^{-5} \ldots 400 \cdot 10^{-5}$, at $\varepsilon_{l}>400 \cdot 10^{-5}$ the deformations $\varepsilon_{R p}$ remain almost invariable. According to the experimental research data, the deformability of concrete strips at shortterm dynamic load, depending on the mentioned above factors, decreases twice.

\section{The theoretical analysis}

The experimental research of the deformability of the concrete stripes between cracks allowed evaluating qualitatively the influence of the studied factors. The quantitative 
evaluation of deformations $\varepsilon_{l}$ influence at different rebars' inclination angles $\alpha$ on the deformability of the concrete strips between cracks is done by mathematic statistical methods [21, 22].

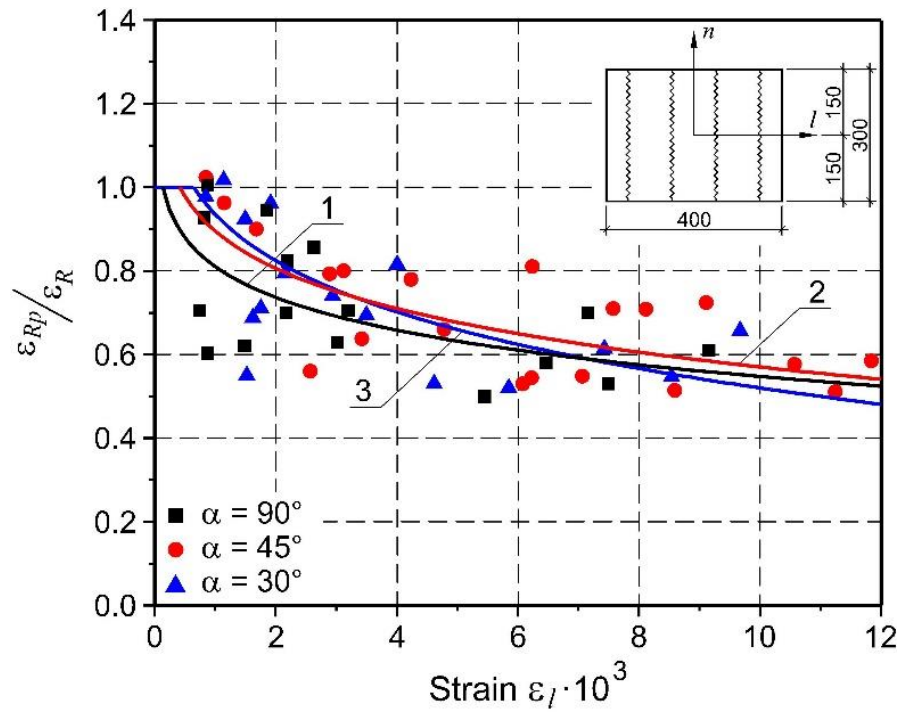

Fig. 3. The change of the deformability of the concrete strips between cracks under a short-term dynamic load depending on the inclination angle $\alpha$ and deformation level $\varepsilon_{l}: 1$-according to the formula (1); 2 - according to the formula (2); 3 - according to the formula (3); $\mathbf{\bullet}, \bullet, \boldsymbol{\Delta}$ - the experimental data.

The experimental data results indicate non-linear change of the concrete strips deformability depending on deformations' level $\varepsilon_{l}$ (fig. 3). At the initial stage the transformation of the data to the linear kind is done, then the evaluation of the data selection is done, including grave errors' sifting and checking the correspondence of the concrete strips' durability between cracks to the normality test. The results of the selections' evaluation are presented in Fig. 4. The grave errors' sifting is done according to Student's test. The checking of the data distribution according to the normality law, done on the grounds of Kolmogorov-Smirnov test and Shapiro-Wilk test criteria, showed their correspondence to the normality distribution law (fig. $4, b, d, f$ ).

The calculated correlation coefficients, characterizing the dependence of the deformability on the tensile strain level $\varepsilon_{l}$, equal to: at $\alpha=90^{\circ}-0.551$; at $\alpha=45^{\circ}-$ 0.652 ; at $\alpha=30^{\circ}-0.798$. This indicates an average and high degree of the studied values ties. 
a)

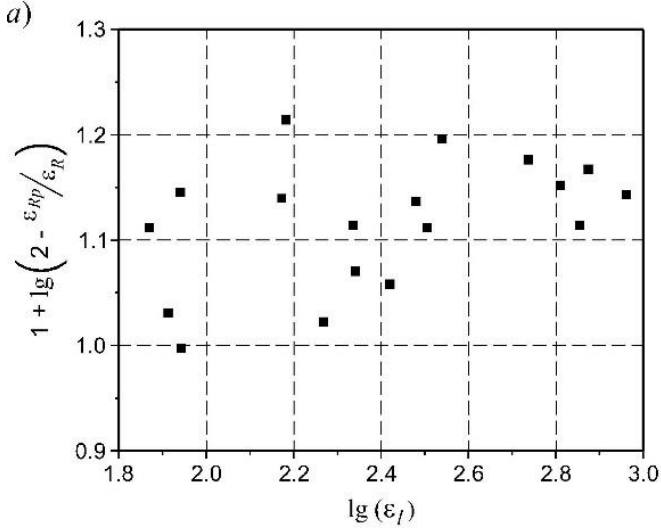

c)

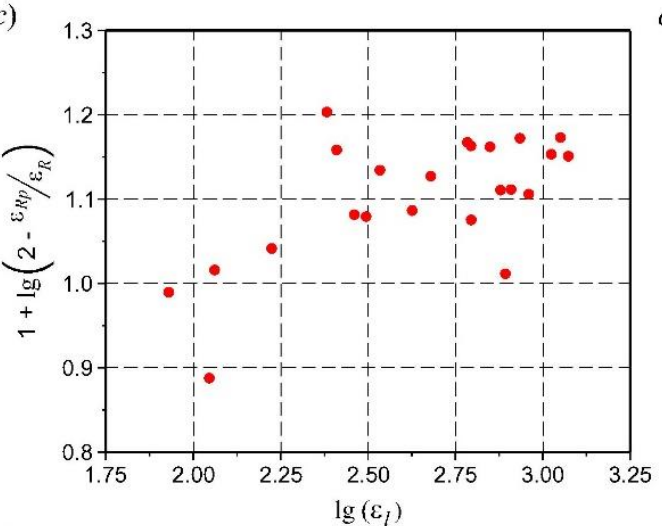

e)

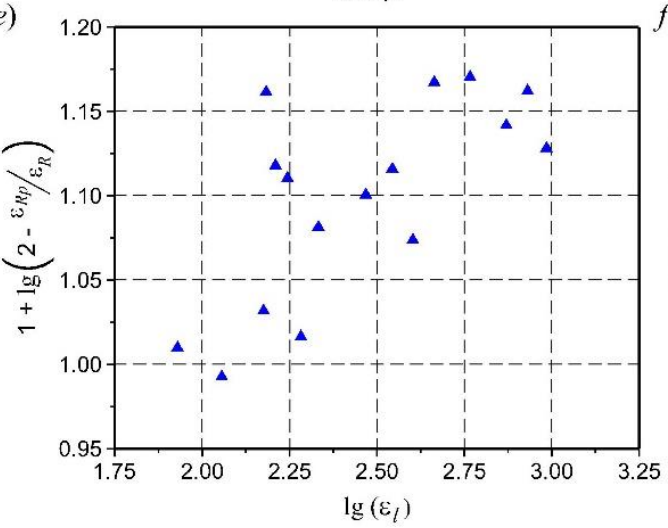

b)

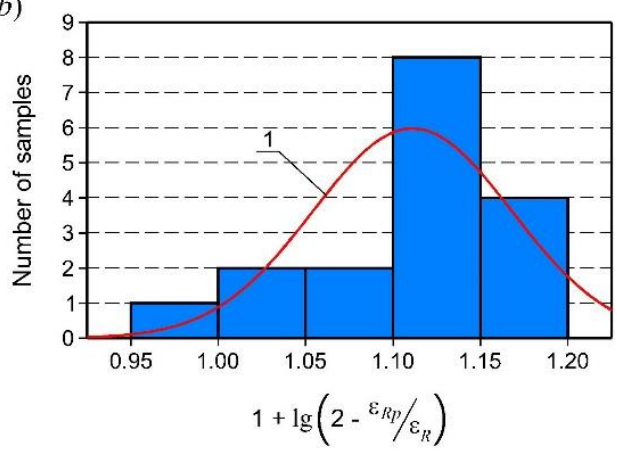

d)

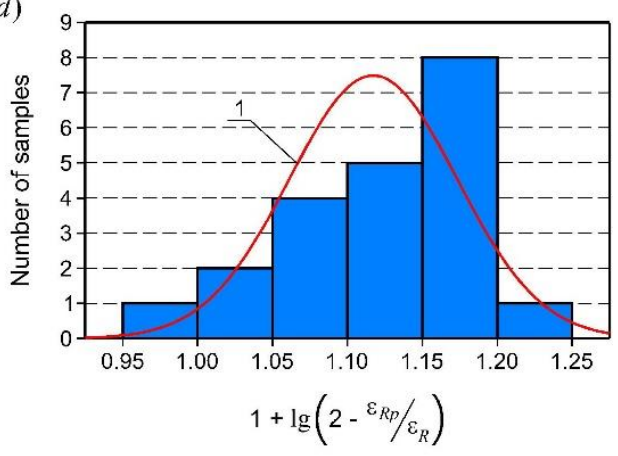

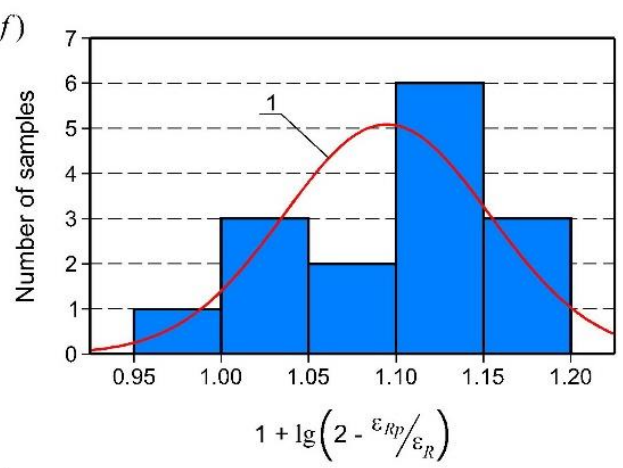

Fig. 4. The deformability change of the concrete stripes between cracks during short-term dynamic loading $(a, c, e)$, and experimental and theoretical distribution of the studied values after bringing them to the linear kind $(b, d, f): a, b-$ at $\alpha=90^{\circ} ; c, d-$ at $\alpha=45^{\circ} ; e, f-$ at $\alpha=30^{\circ} ; 1-$ normal theoretical distribution.

The regression analysis is done according to the methodology presented in the research $[21,22]$. By the least-squares method we got the regression equations which, considering reverse conversion, are of the following kind:

at $\alpha=90^{\circ}$

$$
\gamma_{b p \varepsilon}=\varepsilon_{R p} / \varepsilon_{R}=2-10^{-0.0979+0.0867 \lg \left(\varepsilon_{l}\right)},
$$


- $\quad$ at $\alpha=45^{\circ}$

$$
\gamma_{b p \varepsilon}=\varepsilon_{R p} / \varepsilon_{R}=2-10^{-0.1808+0.112 \lg \left(\varepsilon_{l}\right)}
$$

- $\quad$ at $\alpha=30^{\circ}$

$$
\gamma_{b p \varepsilon}=\varepsilon_{R p} / \varepsilon_{R}=2-10^{-0.259+0.1431 \lg \left(\varepsilon_{l}\right)} .
$$

The evaluation of the obtained expressions significance is done on the basis of F-test criterion which equals: at $\alpha=90^{\circ}-6.253$; at $\alpha=45^{\circ}-14.09$; at $\alpha=30^{\circ}-22.85$. The obtained values are higher than the tabular values corresponding to $5 \%$ of probability being equal to $4.543,4.381$ and 4.667 respectively $[21,22]$. Thereby, the presented dependencies allow determining the deformability of the concrete strips between cracks with confidential probability of 0.95 , laid in regulatory acts.

The analysis of the obtained theoretical dependencies, presented in Fig. 3, shows that the deformations $\varepsilon_{l}$ influence the deformability of the concrete strips samples. The deformations of the concrete strips between cracks, corresponding to ultimate stresses at different inclination angles of the rebars $\alpha$ are comparable; i.e. the value of the angle $\alpha$ almost does not influence the deformability of the samples.

\section{Conclusions}

The results of the experimental-theoretical researches indicate a considerable influence of the samples deformation level in the direction perpendicular to the crack $\varepsilon_{l}$ on the deformability of concrete strips between cracks. The rebars' inclination angle towards cracks $\alpha$ has an insignificant influence on the deformations of the concrete strips $\varepsilon_{R p}$. On the basis of the experimental research data elaboration we offered the dependencies for the determination of the deformability of the concrete strips between cracks. The evaluation of the given formulae indicates a sufficient reliability of the calculated values of the deformations $\varepsilon_{R p}$ of concrete strips.

The reported study was funded by RFBR, project number 19-31-90097

\section{References}

1. G.I. Odnokopilov, D.Ju. Sarkisov, E.A. Butuzov, Proceedings of Tomsk Polytechnical University. Engineering of Geological Resources 329, 122-135 (2018)

2. G.I. Odnokopilov, D.Ju.Sarkisov, Proceedings of Tomsk Polytechnical University. Engineering of Geological Resources 328, 85-95 (2017)

3. G.I. Odnokopilov, O.G. Kumpyak, Z.R. Galyautdinov, D.R. Galyautdinov, Proceedings of Tomsk Polytechnical University. Engineering of Geological Resources 330,110 - 125 (2019)

4. N.I.Karpenko Obshhie modeli mehaniki zhelezobetona [General models of reinforced concrete mechanics] (Strojizdat, Moscow, 1996) (in Russian)

5. N.I.Karpenko, Structural Mechanics and Analysis of Constructions1, 28 - 32 (1984)

6. Z.R. Galyautdinov, News of higher educational institutions. Construction 10, $93-98$ (2010)

7. J. Jones, C. Wua, D.J. Oehlers, A.S. Whittaker, W. Sunc, S. Marksa, R. Coppola, Engineering Structures 31,2825 - 2832 (2009) 
8. B. Chiaia, O. Kumpyak, L. Placidi, V. Maksimov, Engineering Structures 96, 88 - 99 (2015)

9. R. John, S.P. Shah, Impact: Eff. Fast Transient Loadings: Proc 1st Int. Conf. Fast Transient Loadings 8, $37-65$ (1987)

10. Y. Lu, K. Xu, International Journal of Solids and Structures 41, $131-143$ (2004)

11. T. Ngo, P. Mendis, Electronic Journal of Structural Engineering 8, 80 - 89 (2008)

12. V.S. Plevkov, A.I. Malganov, I.V. Baldin, P.V. Stukov, K.V. Kalachev, D.Ju. Sarkisov, 8th Korea-Russia International Symposium on Science and Technology, KORUS, 342 - 344 (2004)

13. Z.R. Galyautdinov, AIP Conference Proceedings 1800, 010001 (2017); doi: $10.1063 / 1.4973016$

14. A. Belarbi, L.-X. Zhang, T.T.C. Hsu, Sociedad Mexicana de Ingenieria Sismica in World Conference On Earthquake Engineering, 1 - 8 (1996)

15. B.Y. Bahn, T.T.C. Hsu, ACI Structural Journal 95, 178 - 193 (1998)

16. F.J. Vecchio, M.P.Collins, ACI Journal 83, 219 - 231 (1986)

17. A. F. Yaremenko, V. S. Gapshenko, Concrete and Reinforced Ferroconcrete 12, 23 24 (1986)

18. Z.R. Galyautdinov, MATEC Web of Conferences 143, 01013 (2018); doi: $10.1051 / 1.4973016$

19. Z.R. Galyautdinov, Bulletin of Tomsk State University of Architecture and Building 6,97 - 105 (2017)

20. O.G. Kumpyak, Z.R. Galyautdinov, D.N. Kokorin Prochnost' ideformativnost' zhelezobetonnyh konstrukcij na podatlivyh oporah pri kratkovremennom dinamicheskom nagruzhenii [Strength and deformability of reinforced concrete structures on yielding supports under short-term dynamic load] (TSUAB Publ.,Tomsk, 2016) (in Russian)

21. E.N.L'vovskijStatisticheskiemetodypostroenijaempiricheskihformu l[Statistical methods of empirical formulas] (VysshayaShkola Publishers,Moscow, 1988) (in Russian)

22. R. Vadzinsky Statisticheskie vychisleniya v srede Excel. Biblioteka pol'zovatelya [Statistical calculations in Excel environement. User's library].- (Peter, StPetersurg, 2008) (in Russian) 